\title{
Embedding research for innovation to meet societal needs in national research systems: experiences from Ghana
}

\author{
Charity Osei-Amponsah ${ }^{1, *}$, Owuraku Sakyi-Dawson ${ }^{2}$, Samuel Adjei-Nsiah ${ }^{3}$, \\ Richard Adu-Acheampong ${ }^{4}$, George Essegbey ${ }^{5}$ and William Quarmine ${ }^{2}$ \\ ${ }^{1}$ Knowledge Technology and Innovation, Wageningen University, The Netherlands \\ 2 Department of Agricultural Extension, University of Ghana, P.O. Box 68, Legon, Ghana \\ 3 International Institute of Tropical Agriculture, IITA, Ghana \\ ${ }^{4}$ Cocoa Research Institute of Ghana, P.O.Box 8, Tafo-Akim, Ghana \\ ${ }^{5}$ Council for Scientific and Industrial Research, Science and Technology Policy Research Institute. P.O. Box CT 519, Accra, Ghana
}

\begin{abstract}
The experiences synthesised in this article indicate how significant effects in two agricultural domains have been achieved by creating pathways for inter-dependent socio-technical and institutional changes, at a range of levels of action, governance and policy-making. The synthesis emphasizes the importance of colearning, experimentation, and critical reflection among a wide network of 'champions' of transformational change on behalf of smallholder farmers and processors. It shows that innovation processes may involve actors along entire value chains, industry leaders at national level, or local level actors seeking to widen the space for change beyond their immediate circle of direct influence. While the research and development initiatives of the domains are shown to have been critical in identifying the constraints and opportunities of smallholders, and also to the effects documented, this was largely because the research effort converged around empirically grounded problems and opportunities identified. The information sought, and the solutions found useful, were determined by the members of innovation platforms that drove the processes of change.
\end{abstract}

Keywords: institutional innovation / cross-scale agricultural transformations / innovation platforms / cocoa / oil palm / Ghana

Résumé - La recherche pour l'innovation aux bénéfices des besoins sociaux au sein des systèmes de recherche nationaux : une nouvelle façon de faire. Cet article montre comment des résultats significatifs ont été atteints dans deux secteurs agricoles par la mise en place de trajectoires de changement sociotechnique et institutionnel, dans les champs des actions de développement, de la gouvernance et des politiques publiques. Cette synthèse met l'accent sur l'importance du co-apprentissage, de l'expérimentation, et de la réflexion critique dans un large réseau de professionnels de l'innovation agissant en faveur des petits producteurs. Elle montre que le processus d'innovation doit impliquer les acteurs de toute la filière, des industriels agissant au niveau national aux petits producteurs locaux soucieux de promouvoir le changement au-delà de leur village. Si les travaux de recherche et de développement sectoriels ont été efficaces pour identifier les contraintes et les opportunités des petits producteurs et pour documenter les effets des innovations, c'est largement parce que les efforts de recherches se sont concentrés sur des problèmes de terrain et sur des opportunités clairement identifiées. Les informations à mobiliser et les solutions à rechercher, ont été identifiées par les membres des plateformes d'innovation qui ont conduit le processus de changement.

Mots clés : innovation institutionnelle / changement agricole / plateformes d'innovation / cacao / huile de palme / Ghana

\section{Introduction}

Agricultural research and extension by National Agricultural Research Systems (NARS) in Africa can be important in addressing societal needs (Ayele et al., 2012). The NARS,

\footnotetext{
* Corresponding author: cdosei72@gmail.com
}

which constitute research institutes, tertiary educational institutions and other organisations (Asare and Essegbey, 2016), have however been weak and ineffective in building the necessary research and development bridges with smallholders. Most of the research institutes focus mainly on specific production constraints such as soil fertility, plant protection, breeding and marketing. The NARS are faced with organisational and institutional challenges, and do not have the capacity 
to analyse the actual constraints and opportunities of smallholders, or assess the institutional contexts in which smallholders operate. The uptake of their research outputs, in the form of technologies and improved practices, by smallholders, has also been poor. Broader systems-oriented research capability, dedicated to analysing and acting on the interacting socio-technical and institutional factors that constrain opportunity for millions of smallholders, who command most of Africa's agricultural resources, remains limited (Sterk et al., 2013; Struik et al., 2014a). There is the need for an institutional change agenda that can formulate research and development arrangements that are 'client-responsive' (Hall and Yoganand, 2004:105). Achieving this agenda means a shift from the linear approach, to a focus on systems innovation.

To this end, international assessments of agriculture's future research needs have emphasized the need for NARS to develop much stronger capacity to undertake Integrated Agricultural Research for Development (IAR4D). An important component of IAR4D is for researchers to engage in action research and learning with other stakeholders, and to create innovation processes that benefit smallholders and their agroenterprises. This article synthesizes a set of experiences supported by the Convergence of Sciences-Strengthening Innovation Systems (CoS-SIS) programme (Hounkonnou et al., 2012; Struik and Klerkx, 2014b) to give insights on the programme's approach. The main features of the programme are outlined in the Introduction to this Issue (Jiggins et al., 2016). Here we first present the Ghana part of the programme and the overall achievements. Thereafter we review and synthesise these experiences under four headings: operational considerations; impacts on Agricultural Research Institutes (ARIs); impacts within the tertiary education sector; impacts on curriculum development at university level. The aim is to draw out the processes by which, beyond the specifics of innovation processes and outcomes at the level of Innovation Platforms (IPs), progress toward the aspirations of IAR4D has become institutionalised in mainstream capacity in Ghana's NARS. The synthesis has been carried out through interaction with the key programme participants over the six months following the end of the programme (mid 2014).

\section{The CoS-SIS programme in Ghana}

From the growing literature on IPs (Ngwenya and Hagmann, 2011; Swaans et al., 2014; Sanyang et al., 2015), we can distinguish two main types: those that act as multistakeholder forums to coordinate the resources and services needed to promote adoption of product technologies and improved practices, that is seeking efficiency and effectiveness in 'business as usual', and those that experimentally seek sociotechnical and institutional changes that strengthen a society's capacity to innovate, that is, transformations in the system of innovation. CoS-SIS deals with the latter, with a focus on innovations such as, experimenting with processors on improving palm oil quality and setting up innovation platform at the district level, as an institutional arrangement to facilitate access to remunerative markets (Osei-Amponsah et al., 2014; Jiggins et al., 2016).

The programme in Ghana, after preliminary scoping and diagnostic studies, consisted initially of three IP experiments, centred on food security and small livestock in Lawra-Nandom district (Fig. 1) in northern Ghana (subsequently discontinued because of staffing changes). A district initiative for smallholder oil palm processing (Osei-Amponsah et al., 2014), based in Kwaebibirem district, and a national initiative involving the major stakeholders in the cocoa industry (Quarmine et al., 2014 with fieldwork conducted in Suhum district).

Each IP was facilitated by a part-time Research Associate (RA), who also tracked and documented the actions and processes involved throughout the programme period. The research associates also participated actively in the development and sharing of new knowledge, and in linking to the IPs, the work of two $\mathrm{PhD}$ students, embedded respectively in the oil palm and cocoa initiatives. The $\mathrm{PhD}$ students were jointly supported by research scientists from social and technical departments of the Wageningen University in the Netherlands and University of Ghana. The research associates in turn were supported by an international group (RA Support Team RAST), who met approximately every four months with them to discuss and analyse their recorded information.

\section{Findings}

\subsection{Operational considerations}

In this section we focus on three considerations that we identify as important in programmes that aspire to help NARS to both 'do different things' and 'do things differently', that is to move towards systemic evolution of capability for IAR4D.

The selection of domains - The CoS-SIS programme took considerable time to identify and scope out the agro-enterprise domains of interest to national stakeholders. It diagnosed sociotechnical and institutional constraints to innovation for smallholders within those domains. Then, it identified individual stakeholders who were positioned and committed to engage in action researching to change the way things were done, and who could be invited to form the innovation platforms (Adjei-Nsiah et al., 2014). Indeed, it could be said that the previous engagement of the programme partners and national stakeholders in a preceding multi-stakeholder action researching programme (CoS-I, 2002-2006, Van Huis et al., 2007) should be viewed as part of the 'time needed'. In contrast to other 'innovation' initiatives, the programme set no initial boundaries to domain selection, the issues to be addressed, or the nature of constraints that would be acted on.

With hindsight, we suggest that the process of domain selection, and the initial choice of the oil palm and cocoa domains, on the one hand, and the food security and small ruminant domain, on the other, were significant to what could be achieved in terms of 'institutionalisation'. The first two domains are of importance to society as a whole, particularly to core political concerns, and to the national economy, though for somewhat different reasons. Oil palm's importance relates to the fact that it involves millions of small-scale producers and processors (mainly women), and thus has high potential to impact incomes, dietary sufficiency, and value chain development for both domestic and export markets. In the cocoa case, the domain remains the most important agricultural sector in terms of its contribution to export revenue and cash crop income. It is evident that both quality and volume must be sustained if Ghana is to keep its share of remunerative export 


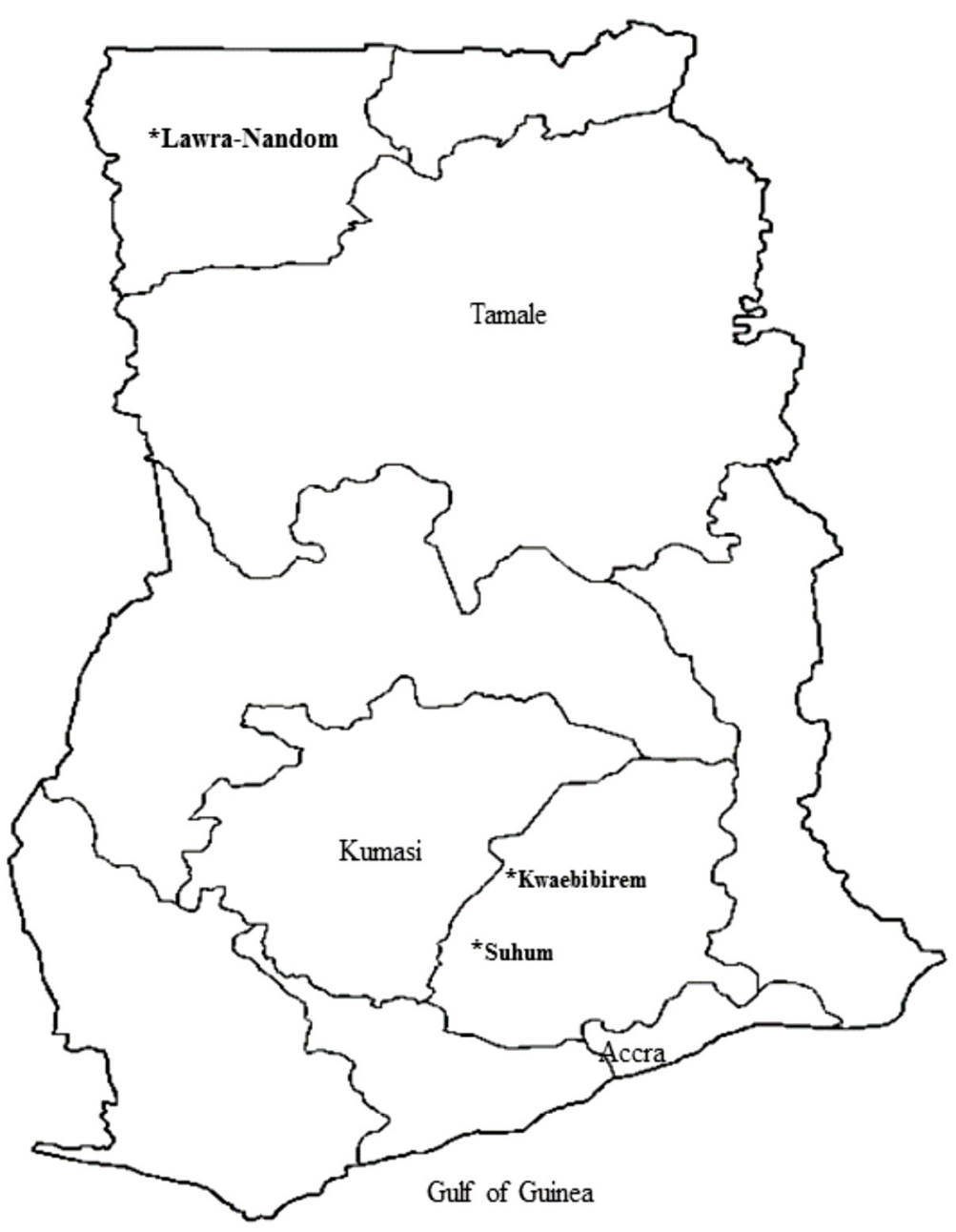

Fig. 1. A map of Ghana showing the CoS-SIS study areas* in Ghana.

Fig. 1. Carte du Ghana montrant les 3 zones d'étude du programme CoS-SIS (*).

markets. In both domains, and notably for cocoa, there are established value chains, functioning service organisations, adequate if not sufficient infrastructures, and a degree of organisation among smallholders themselves. In contrast, although food security is an accepted policy goal, little political attention has been paid to the research needs of smallholders in the drier areas in northern Ghana in general. Specifically, only limited attention has been paid to small ruminants that form an important part of the people's livelihoods. There are only local farmers groups and weak formal organisations, weak service provision, and poorly developed infrastructures. In other words, an IP in this latter case could not be expected to deal with the multiple deprivations, decades of under-investment, and absence of strong commercial drivers in the context.

Interactions between PhD researchers and the IPS - We suggest that IPs of the kind that CoS-SIS has supported derive their energy from their open-ended, experimental approach to effecting change. The provision of new information that clarifies understanding of how natural and social systems work and interact, serves both to challenge pre-existing assumptions about their functioning and effects, and to inspire creative action. The members of the IPs drew on three sources of new knowledge: they themselves conducted inquiries to inform their decisions and actions, they commissioned one-off expert studies, and they drew on the studies conducted by the $\mathrm{PhD}$ students. Participants came to realise that 'no knowledge is worthless', that no single discipline holds a monopoly on 'truth', that discovery involves surprise and shared learning in dynamics processes. It was also evident that involvement by researchers in these processes required patience and the provision of $\mathrm{PhD}$ students by the programme, to conduct research proved especially valuable. Although, it was at times problematic to coordinate the expectations and guidance of the student's multi-disciplinary academic supervisors, and the needs of the IPs for research input, nonetheless, the relationship became in both cases mutually supportive.

The students helped to carry out the initial diagnostic studies, and analysed the process and effects of the various institutional experiments undertaken by the IPs. They were invited throughout the period to present their interim study findings not only to the IPs, and national-level Programme Management Team (PMT), but also at national, regional and international meetings. This contributed to wider processes of reflection, and re-orientation of understanding and practice. Due to this link to the IPs and other actors, the study of the students was made accessible to a larger audience than is normal for a typical $\mathrm{PhD}$ work. Moreover, because it was subject to continuing multi-actor scrutiny, it acquired additional legitimacy through the "tests in 
Table 1. Summary of the transformations achieved in Ghana.

Table 1. Résumé des changements intervenus au Ghana.

Oil palm domain
An inter-connected network of actors has been formed from
smallholders, district assembly, district agricultural development unit,
OPRI scientists, export promotion authority, environmental protection
authority and Ghana regional appropriate technology service.
Smallholder representatives on IP, through awareness creation stopped
the use of tyres as fuel for processing oil palm.

Researcher provided information on good processing practices, and processors have been trained to produce high quality palm oil.

The IPs activities assisted processors to interact with palm oil export companies.

\section{Cocoa domain}

A network of actors has been formed from farmers association, input and license buying company, Ghana cocoa board, Standards authority and advisor to the Minister of Finance and economic planning.

National level policy officers on IP explored and shared information on price setting mechanism, which was communicated to Minister in charge, and influenced the price paid to farmers that season. IP generated information on barriers to input supply, and communicated to policy makers. Now the process of input distribution has been made transparent through public advertisement in national print media practice' to which it was submitted. The members of the IPs, the national-level programme management team, and other actors for their part through study visits to the various stakeholders and field-level experiments that the students were engaged with, had access to a 'reference field of operations' and to social and institutional spaces that were created for trying out 'novel ways of doing things'.

The Ghana CoS-SIS evidence further suggests that these interactions created new social capital and knowledge networks that other researchers already are benefiting from (see further below). A new pathway and skills have been created for research and development in the study areas. We consider it important to note that these pathway and skills were not only enjoyed by researchers and elite members of the CoS-SIS community; the farmers, processors and other local actors also have learned a new way of interacting in their own interests. For example, this group of actors are able to have open discussions with researchers and other stakeholders; they have voice and visibility at meetings, and confidence to share their ideas and knowledge, not least because they have a better understanding of the domain and value chains in which they are engaged; but they have also acquired knowledge that directly benefits their own production, processing, and marketing enterprises. They have become ambassadors of the research output among their peers and other stakeholders.

The IPs' interactions with political authorities - Varying experiences and opinions have been debated regarding the inclusion of politicians (however defined) in IPs and/or PMTs. The CoS-SIS programme consciously decided from the outset not to include practising politicians, because of the risks of cooption to party political ends. Interaction with political authorities, however, came to be seen as a valuable strategic resource, at a range of levels. For instance, members of the cocoa IP had personal and professional links with the highest levels of the government and civil service that provided significant channels of communication and influence, concerning the revision of the mechanism used in setting price of cocoa paid to farmers (Adu-Acheampong et al., 2016, in this issue). In the case of oil palm, the invitation to present the findings of the study commissioned by the IP on the health and environmental impacts of processors' use of old lorry tyres as fuel, to the District Assembly of Kwaebibirem, opened the way to a new bye-law, re-location of processing sites to the edges of settled areas, and the continuing support of the District Assembly for the IP's evolving strategy (Adjei-Nsiah and Klerkx, 2016, in this issue). In both cases, other political authorities such as the chiefs and Assembly members also played significant roles in enabling institutional solutions to identified constraints. For example, in one of the oil palm processing communities, a chief banned the use of lorry tyres as fuel source and imposed a fine of fifty Ghana Cedis $( \pm 12 €)$ on anyone who contravened the ban. The banning of the use of tyres was further enhanced by the presence of two of the Assembly Members on the IP.

We suggest that these experiences indicate the importance of engaging with political authorities, not as advocates of party political agendas but as partners in a dialogue. This must however be initiated, only once evidence becomes available of what can be gained by transforming the way things have been done. We summarise the evidence for some of the transformations achieved in Table 1.

Initiation \& embedding CoS-SIS approach within the University of Ghana - The University of Ghana at Legon was a CoS-SIS programme partner. From the start, high level actors (e.g. deans and heads of departments) were engaged by the members of the PMT and national coordinator. They presented CoS-SIS as an opportunity for the university to re-orientate education and research training for students. Their participation in CoS-I (the first phase of the program on Convergence of Sciences) had encouraged them in this view, specifically, the fact that three Ghanaian PhDs trained under CoS-I had each been guided effectively by supervisory teams composed of mixed disciplines, from both the University of Ghana and Wageningen University. The principal means by which their involvement has been secured were:

- frequent interactions about how the university could build the approach into the university's capacities and courses, in this way developing high level social capital through dialogue and information-sharing;

- nurturing and supporting the role of 'champions', through continued commitment to CoS-SIS activities, network building; 
- strategic arrangement with regard to the future generations of academic leaders and decision-makers. The potential high flyers were invited, for example, to be presenters at CoS-SIS meetings and to act as members of the $\mathrm{PhD}$ supervisory teams;

- a former Director of the Council of Scientific and Industrial Research (CSIR), participated in numerous national, regional and international meetings organised by CoSSIS. He facilitated the understanding of the CoS-SIS approach within inter-connecting science networks.

Engaging with the Agricultural Research Institutes (ARIs) The three agricultural research institutes closely connected with the domains and with the PhD students' work, were the Cocoa Research Institute of Ghana (CRIG), Oil Palm Research Institute (OPRI) and Animal Research Institute (ARI) all of the Council for Scientific and Industrial Research (CSIR). In the course of 2012-2013, they requested CoS-SIS to guide them through processes of internal capacity development to carry out diagnostic research and work with innovation platforms. The groundwork for this request was developed strategically by CoS-SIS, principally by means of inter-personal and professional networking, through their membership in the PMT and Domain Advisory Committees, the evidence presented in CoSSIS publications, and their participation in CoS-I and CoS-SIS meetings and supervisory teams. However, another important factor is that Ghana has a research structure that is receptive to the kind of evidence provided by the programme and a hunger in the ARIs to respond to policy-makers' demands for accountability to make science work for society.

The ARIs' request emerged as follows. Throughout 2011-2012 they hosted the PhD students and held joint workshops in their own institutes, with an open invitation to whoever they wanted to attend. The Directors-General of the institutes were invited to make the opening statements, define agendas, and explore participants' researching practices in an open-ended fashion. The first part of the workshops addressed the questions of research for whom and for what? What are the consequences if research is directed mostly to industrial agriculture's concerns and there is little uptake among smallholders? Who has the mandate to serve smallholders' needs? What would a research pathway for these target clients look like? Would CoS-SIS experiences help? This was followed by small group work by each institutes' staff, exploring what would be useful to their own work and why, what not and why. This was followed by plenary consensus-building and decisions about how CoS-SIS and the ARIs could work together to 'learn their way' to achieve the things they had identified as beneficial to their own research and development interventions. The previous section was then followed by planning the learning activities, who does what, when, cost-sharing arrangements and an indicative budget. Each institute appointed a focal person to begin to build and lead the internal change network.

This activity had not been foreseen in CoS-SIS' financial planning but since part of the budget had not been needed, it was re-allocated to cover the costs of one person per ARI (to carry out an exploratory study or value chain analysis in what is happening, who is involved, why do they act as they do, the history and the context, by carrying out small surveys, PRAtype interactions, documentary analysis). The multi-level perspective (Geels, 2005) was used as a frame of analysis, to point the way towards unsuspected constraints, opportunities and new research questions. These field exercises were followed by joint review of their experiences. The lessons of experience were written up as concise Briefing Notes, to share within own institutes. Three staff from each institute (on a cost-sharing basis) were then tasked to write research proposals related to the identified opportunities and research questions. A three-day write shop was held at the end of 2013 to ensure that the proposals were ready for submission at next call.

Curriculum development - The intention to develop the university's curriculum emerged during CoS-I. A threepronged effort was initiated, to create courses for undergraduates, Masters and PhD students, that would introduce them to multi/transdisciplinary research approaches and field inquiry methods. Although the proposed new courses were approved in principle, subject to further specification of their contribution to innovation in the agriculture sector, under CoS-I it proved impossible to further develop these elements before the programme ended.

As CoS-SIS began, the educational authorities within Ghana and the West Africa region, expressed renewed interest in curriculum development to support innovation. Part of the CoS-SIS budget was allocated to address this challenge. Within the university of Ghana, internal discussions were launched at departmental and college levels. It was concluded that add-ons 'were not sufficient' to achieve the transformations required. Therefore, the department of agricultural extension was asked to spearhead the process and lead the other departments (crops, soils, economics, animal sciences and engineering) involved in agriculture. It was recognised from the outset that the inputs from all the departments was needed to make the proposed transformations successful.

In the first half of 2013, CoS-SIS engaged a consultant to facilitate further negotiations among the department heads and senior staff concerning the desired learning outcomes and curriculum design. His inquiries surfaced the need for clarification of the nature of 'innovation research': research on innovation, that is how innovation has occurred, or research for innovation? The consensus choice was 'research for innovation' (although research on innovation would be allowed where justified). The consultant also worked on similar curriculum developments with CoS-SIS partners in Benin and Mali.

The next step was to convene a regional workshop, held in Cotonou, Benin. The heads of all participating departments, the Dean and coordinator of the School of agriculture, the PMT chair, and the former Dean of international programmes, all attended from Ghana. The participants debated if they should aim for a common regional curriculum or each country should develop its own. They decided on the latter in order that the design and content would meet each country's needs and context. It was agreed that the designs would include courses to support programmes for $\mathrm{PhD}$, Masters and short course students (with the latter open also to students from outside the university, to accommodate the needs of the ARIs and others). Each country group further specified courses within each programme. In the case of Ghana, it was decided that the courses would be offered in the College of Agriculture in the mainstream programme, and as electives for other Colleges.

The draft proposals were presented to the College of Agriculture for validation. A national stakeholders' workshop 
(including participants from NGOs, the Ministry of Food and Agriculture, farmers' umbrella organisations, processors' associations, research institutes, and chiefs and civil society leaders) was held, at which the proposals were further discussed, amended and validated by a wider set of interests.

After final revision, the new curricula was submitted to the university authorities at the end of 2014, and the preparation of course materials and information booklets was initiated. These processes however, could not be followed through to the end, to get the approval of the university for the teaching of the courses. This was mainly because it was anticipated that the introduction of the new courses would require funds in the form of scholarships to motivate the first batch of students to be trained with the new curriculum. Since the programme had ended there was no more funding to continue with the budget of further curriculum development activities. There was also the fear of which academic qualifications or degrees would be offered to the students to make them employable within the Universities and ARIs in Ghana, since they have a system of awarding degrees or employing in general mono-disciplines like extension, animal science, and this is not likely to change. To make matters worse, the national coordinator who was spearheading the process from the department of extension, died during the period, and the activities came to a standstill.

Currently, it is evident that the department of extension have picked up some aspects (topics) of the courses in the new curriculum and incorporated into the existing course structure to make it relevant to current discourse in agricultural extension and development, without necessarily changing the degree to be awarded, it still remains Masters and $\mathrm{PhD}$ in Extension.

\section{Conclusion}

We suggest that the experiences and evidence synthesised in this article identify an effective pathway towards innovation in key institutions governing agricultural research and development for smallholders. The actions taken contributed toward changes in norms and attitudes among key decision makers at multiple levels, to material change in practices and incentives, and to a different way of grounding evidence of "what works better' in a context. They emphasise the importance of combining action researching and formal studies, and of engaging as widely as practical a diverse range of individuals and organisations in the processes of learning, peer review of new information, and managing the information strategically to bring about change. The experiences show that innovation emerges from the interaction among multiple stakeholders in the agricultural domains that generates concerted action. By facilitating an IAR4D programme, the NARS stands in a better position to contribute to a more integrated systemic innovation needed to meet societal needs, particularly of smallholders. However, NARS need to build their capacity in the understanding of the innovation system approach and internally mobilise resources (funding), to institutionalise such initiatives, so that they do not continue with 'business as usual'.

Our conclusions or perhaps, rather, hypotheses for further testing, are: while IPs of the CoS-SIS kind may offer opportunity for actors to engage in participatory research for development in the conditions in which the food security IP was initiated, they offer no special advantage or opportunities for 'institutionalising' systemic change; and IPs function more optimally in domains where there are strong external actors (commercial, governmental, societal) with a stake in seeing that innovation capability is developed within the domains.

Acknowledgements. The authors thank the CoS-SIS community in Ghana for their contributions to drafting this synthesis. They particularly acknowledge the contribution of Professor Sakyi-Dawson, who died during the article's completion. The financial support of the Dutch Ministry of Foreign Affairs is also gratefully acknowledged.

\section{References}

Adjei-Nsiah S, Klerkx L. 2016. Innovation Platforms and institutional change: the case of small-scale palm oil processing in Ghana. Cah. Agric. 25(6). DOI: 10.1051/cagri/2016046

Adjei-Nsiah S, Sakyi-Dawson O, Klerkx L. 2014. Facilitating institutional change in West-Africa: the CoS-SIS experience. In: Triomphe B, Waters-Bayer A, Klerkx L, Schut M, Cullen B, Kamau GE. eds. Innovation in smallholder farming in Africa: recent advances and recommendations. Proceedings of the International Workshop on Agricultural Innovation Systems in Africa (AISA). Nairobi, Kenya. Montpellier: CIRAD, pp. 29-31. Available from http://www.farmaf.org/images/documents/related_materials/ AISA workshop proceedings final March 2014.pdf

Adu-Acheampong R, Jiggins J, Tei Quartey $\bar{E}$, Nana Karikari M, Jonfia-Essien W, Quarshie E, et al. 2016. An innovation platform for institutional change in Ghana's cocoa sector. Cah. Agric. 26(1), submitted.

Asare R, Essegbey GO. 2016. Funding of agricultural research and development in Ghana: The case of council for scientific and industrial research (CSIR). Technol Invest 7: 40-50. Avalaible from http://dx.doi.org/10.4236/ti.2016.72006.

Ayele S, Duncan A, Larbi A, Khanh TT. 2012. Enhancing innovation in livestock value chains through networks: lessons from fodder innovation case studies in developing countries. Sci Public Policy 39: (3)333-346.

Geels FW. 2005. Processes and patterns in transitions and system innovation. Refining the co-evolutionary multi-level perspective. Technol Forecase Soc 72: 681-696

Hall AJ, Yoganand B. 2004. New institutional arrangements in agricultural research and development in Africa: Concepts and case studies.Innovations in Innovation: Reflections on Partnership, Institutions and Learning. In: Hall AJ, Yoganand B, Sulaiman RV, Raina RS, Prasad CS, Naik GC, Clark NG, eds. New Delhi and Andhra Pradesh, India: CPHP/ICRISAT/NCAP, pp. 105-131.

Hounkonnou D, Kuyper T, Kossou D, Leeuwis C, NederlofC, Röling N, et al. 2012. An Innovation System Approach to Institutional Change: Smallholder Development in West Africa. Agr Syst 108: 74-83.

Jiggins J, Hounkonnou D, Sakyi-Dawson O, Kossou D, Traoré M, Röling N, et al. 2016. Introduction: Innovation Platforms to support smallholder development - experiences from sub-Saharan Africa. Cah. Agric. 25(6), DOI: 10.1051/cagri/2016051.

Ngwenya H, Hagmann J. 2011. Making innovation systems work in practice: experiences in integrating innovation, social learning and knowledge in innovation platforms. Knowl Manag Dev J7: (1)109-124.

Osei-Amponsah C, Stomph TJ, Visser L, Sakyi-Dawson O, AdjeiNsiah S, Struik P. 2014. Institutional change and the quality of palm oil in Benin. IJAS 12: (3)233-247.

Quarmine W, Haagsma R, van Huis A, Sakyi-Dawson O, Obeng-Ofori D, Asante F. 2014. Did the price related reforms in Ghana's cocoa sector favour farmers? IJAS 12: (3)248-262 
Sanyang S, Jean-Baptiste TS, Kuiseu J, Coulibaly N'Tji, Konaté L. 2015. A paradigm shift in African agricultural research for development: the role of innovation platforms. IJAS. DOI: 10.1080/14735903.2015.1070065

Sterk B, Kobina AC, Gogan AC, Sakyi-Dawson O, Kossou D. 2013. Five years after: the impact of a participatory technology development programme as perceived by smallholders in Benin and Ghana. International J Agric Education Ext 19: (4)361-379.

Struik P, Klerkx L, van Huis A, Röling N. D 2014a Institutional change towards sustainable agriculture in West Africa. IJAS 12: 201-213.
Struik P, Klerkx L. 2014b. Institutional Change towards sustainable agriculture in West Africa. Spec Issue IJAS 12: (3)201-382.

Swaans K, Boogaard B, Bendapudi R, Taye H, Hendrickx S, Klerkx, L. 2014. Operationalizing inclusive innovation: lessons from innovation platforms in livestock value chains in India and Mozambique. Innovation Dev 4: (2)239-257.

Van Huis A, Jiggins J, Kossou D, Leeuwis C, Röling N, SakyiDawson O, et al. 2007. Agricultural research to reduce rural poverty. Can convergence of sciences support innovation by resource-poor farmers in Benin and Ghana? Spec Issue IJAS 5: (2-3)91-108.

Cite this article as: Osei-Amponsah C, Sakyi-Dawson O, Adjei-Nsiah S, Adu-Acheampong R, Essegbey G, Quarmine W. 2016. Embedding research for innovation to meet societal needs in national research systems: experiences from Ghana. Cah. Agric. 25 : 65004. 